\title{
Mucinous adenocarcinoma metastatic to the iris, ciliary body, and choroid
}

Wills Eye Hospital, Jefferson Medical College, Thomas Jefferson University, Philadelphia, PA, USA, Oncology Service

W E Lieb

J A Shields

C L Shields

Glaucoma Service

G L Spaeth

Correspondence to: Jerry A Shields, MD Director, Oncology Service, Wills Eye Hospital, Ninth and Walnut Streets, Philadelphia, PA 19107, USA.

Accepted for publication

11 January 1990

\begin{abstract}
A 67-year-old woman presented with signs of severe intraocular inflammation and secondary glaucoma. The initial diagnosis was uveitis, and an anterior chamber paracentesis with cytological study of the aspirate failed to establish an aetiological diagnosis. After three trabeculectomies had failed to control the intraocular pressure, the blind eye was enucleated. On histopathological examination a mucinous adenocarcinoma was found to cover diffusely the iris surface and to involve the ciliary body and peripheral choroid. The patient subsequently developed evidence of widespread metastatic disease and died shortly thereafter. Although a primary tumour was never found, histochemical and immunohistochemical studies of the enucleated eye suggested that the lesion originated in the gastrointestinal tract. In cases of intractable glaucoma and anterior chamber inflammation, metastatic carcinoma should be included in the differential diagnosis, and efforts should be made to substantiate the diagnosis by a systemic examination or a biopsy.
\end{abstract}

The commonest primary tumours to metastasise to the anterior uvea are breast, lung, and gastrointestinal tract carcinomas. ${ }^{1-5}$ Rare tumours such as bronchial carcinoid, renal cell carcinoma, and squamous cell carcinoma of the cervix have been reported to metastasise to the anterior uvea. ${ }^{6-10}$ However, in $9 \%^{4}$ to $18 \%^{2}$ of cases the primary tumour location is unknown despite extensive investigation.

Most metastatic carcinomas occur in the posterior choroid, and only $5 \%^{14}$ to $11 \%^{2}$ occur in the iris and/or ciliary body. Metastatic tumours to the anterior segment often present as solitary or multiple nodules on the iris or in the anterior chamber angle, with a diffuse shedding of cells into the anterior chamber simulating a severe anterior uveitis. ${ }^{11-14}$ Metastatic tumours to the iris present with glaucoma in $7 \%$ of cases and later develop increased intraocular pressure in about half the cases. ${ }^{3}{ }^{15} \mathrm{We}$ report a case of a metastatic carcinoma to the anterior segment of the eye that simulated uveitis and produced severe secondary glaucoma.

\section{Case report}

In December 1984 a 67-year-old woman presented with an inflamed left eye. She was found to have an 'idiopathic iritis' and was treated with topical corticosteroids. Several weeks later she developed an intraocular pressure of $62 \mathrm{mmHg}$ in the left eye. The glaucoma did not respond to conventional therapy, and the patient subse- quently underwent trabeculectomy in March 1985. This procedure failed to control the elevated intraocular pressure in her left eye.

The patient was seen in consultation at another hospital in June 1985. The right eye was entirely normal. The intraocular pressures were $15 \mathrm{mmHg}$ in the right eye and $40 \mathrm{mmHg}$ in the left. The cornea was diffusely oedematous. Unusual translucent material was present on the anterior iris surface near the iridectomy site. A second trabeculectomy was performed during which translucent material was removed from the anterior chamber. Histological examination of the material disclosed fibrinous strands with acute inflammatory cells and macrophages. No bacteria, fungi, or malignant cells were found.

Despite the two prior trabeculectomies the patient continued to have a painful left eye with a raised intraocular pressure and was sent for further examination to the Glaucoma Service of Wills Eye Hospital. The intraocular pressures could not be controlled by conservative medical measures such as oral carbonic anhydrase inhibitors, $\beta$ blockers, or topical corticosteroids. Cyclocryotherapy to $180^{\circ}$ of the ciliary body was performed. Despite frequent topical corticosteroid therapy the anterior chamber inflammation could not be controlled. Postoperatively ultrasonography demonstrated inferonasal and inferotemporal choroidal detachments. Although the intraocular pressure was relatively well controlled, white debris continued to accumulate in the anterior chamber. An intraocular tumour was suspected, and the patient was referred to the Ocular Oncology Service at Wills Eye Hospital.

The patient had a history of a breast biopsy for a.mass that had proved to be benign. There was no history of cancer. Visual acuity was $6 / 9$ in the right eye and light perception in the left. Applanation intraocular pressures were $7 \mathrm{mmHg}$ in the right eye and $13 \mathrm{mmHg}$ in the left eye. The right eye was entirely normal. The left eye had a clear cornea and mild conjunctival injection. In the anterior chamber a diaphanous yellowish white material covered most of the anterior iris surface, and a moderate amount of cell material and flare were noted as well as a small hyphaema (Fig 1). There were no nodules in the iris or anterior chamber angle. The fundus could not be visualised because of the anterior chamber reaction and posterior synechiae.

The chronically inflamed, blind painful eye was enucleated in October 1985.

\section{MACROSCOPIC EXAMINATION}

The specimen consisted of a soft left eye measuring $24 \times 24 \times 24 \mathrm{~mm}$, with a short section of optic nerve attached. The cornea was clear and 
Figure 1: Slit-lamp photograph of the anterior segment after a repeated trabeculectomy. There is a small hyphaema inferiorly. Nasally white fluffy material can be seen.

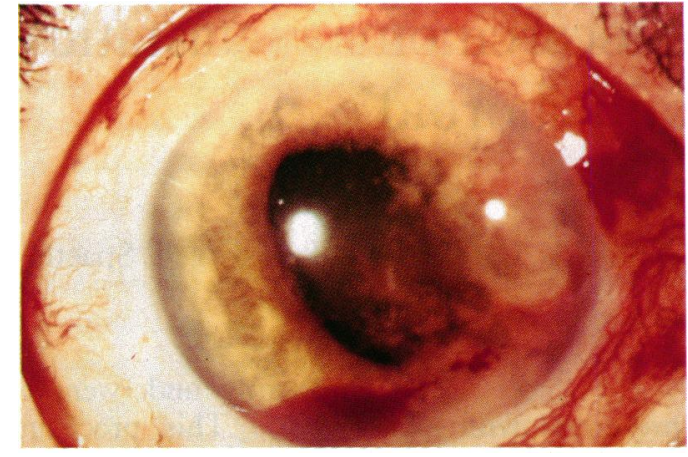

measured $12.5 \times 11.5 \mathrm{~mm}$. The anterior chamber was almost completely filled with a fluffy white material (Fig 2). There was good transillumination, with no shadows seen.

The eye was opened vertically to include the prior iridectomy sites. On opening the globe the peripheral choroid and ciliary body were found to be thickened superiorly and covered with white material. There was also condensation of the vitreous in a funnel shaped pattern from the disc to the posterior surface of the lens.

\section{MICROSCOPIC EXAMINATION}

The cornea appeared normal except in its inferior part, where a layer of cuboidal cells was growing on to its posterior surface (Figs 3, 4). The cells had vacuolar cytoplasm and rather large atypical nuclei. This monolayer of cells grew along the surface of all structures in the anterior chamber and covered most of the trabecular meshwork. It reflected over the anterior iris surface where it assumed a papillary frond pattern (Fig 5). In some sections these cells grew around the pupillary margin on to the posterior surface of the iris and extended back to the pars plicata and the pars plana. In the ciliary body the mucin-producing cells formed small cysts containing mucinous material. In the anterior part of the choroid tumour cells were also seen forming duct-like structures with a central area of mucin. The remainder of the choroid, retina, and sclera was normal. The mucinous material stained positive with Alcian blue and was resistant to hyaluronidase. The material also stained positive with periodic acid

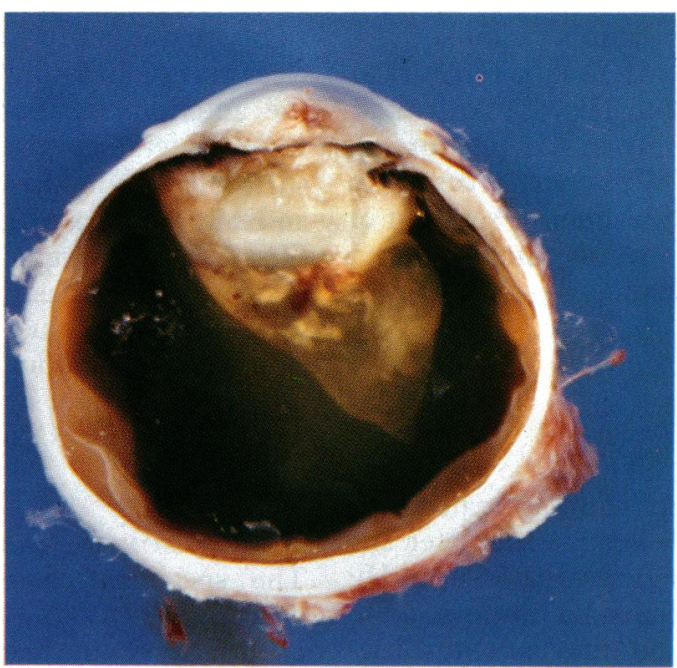

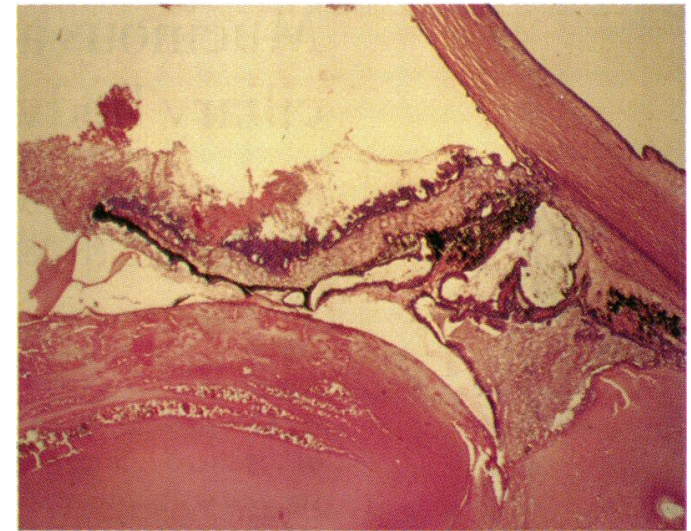

Figure 3: Low-power photomicrograph showing parts of the anterior segment. There is a monolayer of cells growing on the back surface of the cornea, covering the anterior chamber angle, the anterior and posterior iris surface, and extending up to the pars plana. Posterior synechiae are present.

(Haematoxylin-eosin, $\times 5$.)

Schiff and mucicarmine stains. Immunoperoxidase stains for carcinoembryonic antigen (CEA) were highly positive, suggesting that the primary tumour probably originated from the gastrointestinal tract.

Subsequently the patient underwent a complete evaluation for a primary malignancy. The results of the physical examination, including a breast examination, computed tomography of the head and abdomen, upper and lower gastrointestinal (GI) tract, proctoscopy, liver function studies, electrolytes, and complete blood count were normal. The only abnormality found was on the computed tomograph of the chest, in which a small pleural effusion and two pleural nodules were discovered. Aspiration of the pleural fluid revealed mucin producing adenocarcinoma cells with a high CEA level of $390 \mathrm{ng} / \mathrm{ml}$ (normal $<5.0 \mathrm{ng} / \mathrm{ml}$ ).

Owing to these findings the patient was reexamined for a primary tumour in the gastrointestinal tract, but none was found. She died six months later of pulmonary and cardiac failure secondary to widespread metastases. Permission for a necropsy was not granted.

\section{Discussion}

Metastatic tumours to the eye are probably the commonest intraocular malignant tumours of adults. As has been shown in several series, they most commonly involve the posterior choroid. ${ }^{1-4}$ Ophthalmological studies do not reflect the true incidence of these tumours because many metastases are never clinically discovered owing to their occurrence in patients with end stage disease, who do not undergo ocular examination.

Metastatic tumours to the iris and ciliary body may simulate an inflammatory process. In one series 10 out of 26 patients with metastases to the anterior segment presented with uveitis. ${ }^{3}$ Anterior segment metastasis led to secondary glaucoma in $56 \%$, and many of these cases underwent antiglaucomatous surgery. ${ }^{3}$ The mechanism of the glaucoma in these cases is often two-fold. Besides the thin sheet of tumour cells covering the surface of the iris, the anterior chamber angle, and the posterior surface of the cornea, the production of mucus leads to a
Figure 2: Gross specimen shows white material and haemorrhage in the anterio chamber, a dense cataract, thickening of the ciliary body, and vitreous haemorrhage. 


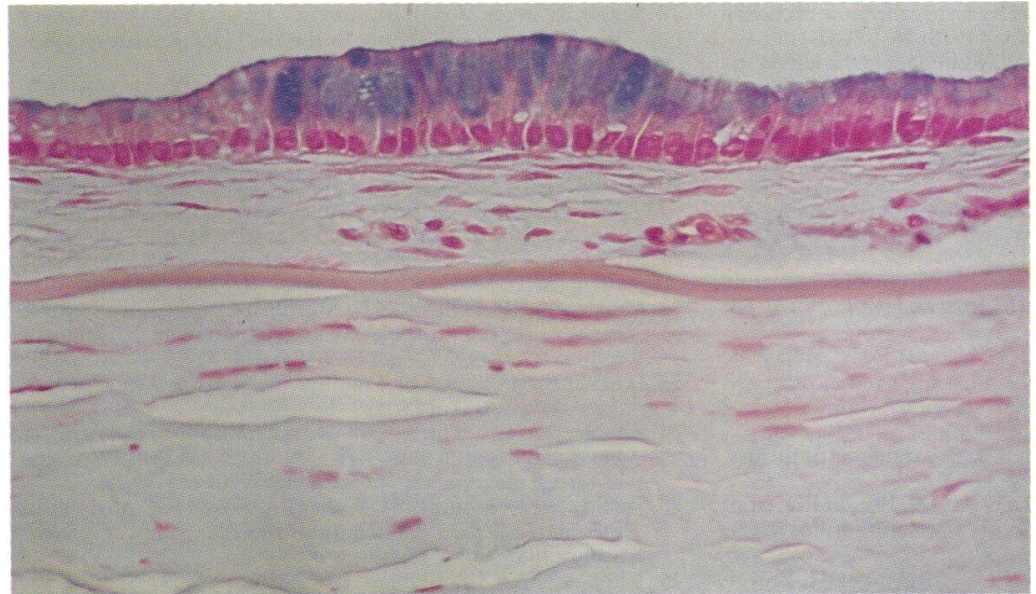

Figure 4: high-power photomicrograph showing single layer of tumour cells forming a retrocorneal membrane and covering the peripheral cornea. (Alcian blue, $\times 150$.)

'mucogenic glaucoma'.' In some instances tumour induced iris neovascularisation can cause occlusion of the anterior chamber angle and increase of intraocular pressure. In a few cases the diagnosis was made clinically or by cytological examination of the specimen from anterior chamber paracentesis. ${ }^{17-19}$ The majority of anterior segment metastases were diagnosed after enucleation for severe late complications of inflammation and secondary glaucoma, as occurred in our case. In several cases an aqueous specimen showed only a non-specific inflammatory reaction. However, since a large number of primary tumours that arise from the lung, breast, or gastrointestinal system produce CEA, measuring the serum level and levels of this antigen in the aqueous should be considered more often. ${ }^{1720-22}$

In our specimen the carcinoma cells covering the anterior and posterior iris surface stained positive for CEA. This, in combination with the excessive mucin production and the papillary frond-like pattern, suggested the gastrointestinal tract as the most likely site of the primary

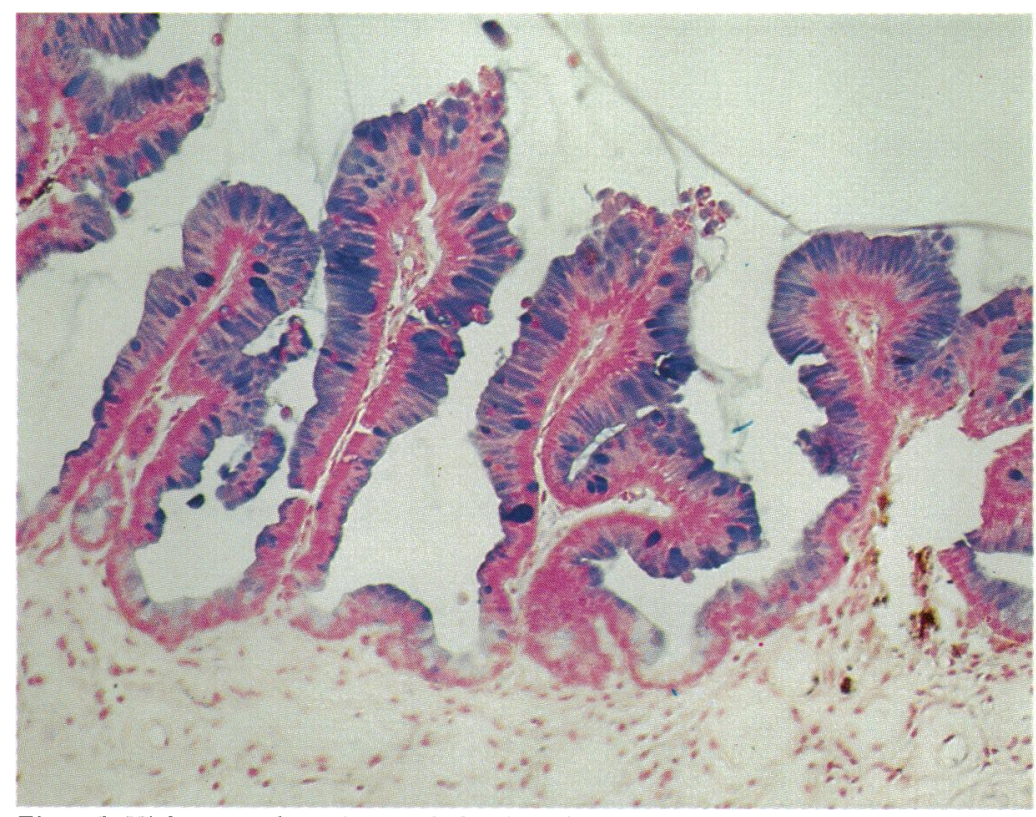

Figure 5: High-power photomicrograph showing adenocarcinoma cells growing in a frond like pattern on the anterior iris surface, resembling colonic mucosa. (Alcian blue, $\times 150$.) tumour. A similar case with the primary carcinoma located in the caecum has been reported.'

Several conditions should be included in the differential diagnosis of metastatic cancer to the iris and ciliary body. They include iris melanoma, adenoma of the ciliary pigment epithelium, and granulomatous uveitis. In contrast to amelanotic melanomas of the iris or ciliary body, iris metastases are generally more gelatinous, friable, and yellow. A metastasis may not present as a solid tumour nodule but rather as a diffuse sheath of cells covering the anterior iris surface. Only rarely do metastases infiltrate the deep iris stroma or break through the iris pigment epithelium into the posterior chamber. Two-thirds of all uveal metastases are purely cellular and do not have stroma vessels that could be demonstrated on biomicroscopy or fluorescein angiography..$^{23}$

Primary adenomas and adenocarcinomas of the non-pigmented ciliary epithelium are extremely rare, and metastases have not been known to occur. ${ }^{24}$ As Jakobiec et $a^{26}$ have pointed out, primary ciliary mucinous tumours tend to grow in strings and garlands and do not form complete lumina.

Iris metastases can seed cells into the anterior chamber forming a tumour-induced pseudohypopyon.' Other lesions which may be confused with anterior segment metastases include granulomatous uveitis (sarcoidosis or syphilis) and retained foreign bodies. The examination should be directed to exclude these lesions.

In cases of intractable glaucoma with severe persistent anterior segment inflammation a complete systemic examination should be undertaken to exclude a primary malignancy. If that shows nothing, an anterior chamber aspirate and/or a peripheral iridectomy may be performed at the time of the filtering procedure and sent for histological examination. If the diagnosis of a mucin-producing tumour is made, a distant primary tumour should be suspected, and a more extensive diagnostic examination should be undertaken. If no primary tumour is found and the patient is systemically well, then radiotherapy to the eye should be administered, approximately 3000 cGy-4000 cGy being given. ${ }^{27}$ If a primary tumour is found, ocular radiotherapy may be withheld until a response to chemotherapy or hormonal therapy is assessed..$^{28}$

This work was supported in part by the Ocular Oncology Fund and the Oncology Research Fund, Wills Eye Hospital, and in par by the Black Patch Invitational Golf Tournament, Downington, PA.

1 Shields JA. Diagnosis and management of intraocular tumors. St Louis: Mosby, 1983: 278-321.

2 Ferry AP, Font RL. Carcinoma metastatic to the eye and orbit. I. A clinicopathologic study of 227 cases. Arch Ophthamol 1974; 92: 276-86.

3 Ferry AP, Font RL. Carcinoma metastatic to the eye and orbit. II. A clinicopathological study of 26 patients with carcinoma metastatic to the anterior segment of the eye. Arch Ophthalmol 1975; 95: 472-82.

4 Stephens RF, Shields JA. Diagnosis and management of cancer metastatic to the uvea. A study of 70 cases. Ophthalmology 1979; 86: 1336-49.

5 Miller B, Rush P, Luntz MH. Metastatic carcinoma of the.iris. Ann Ophthalmol 1980; 12: 514-8.

6 Barsky D. Unusual tumor of the iris: a rare initial clinical manifestation of metastatic adenocarcinoma of the tail of the pancreas. Ann Ophthalmol 1978; 10: 1539-43. 
7 Rodrigues MM, Shields JA. Iris metastasis from a bronchial carcinoid tumor. Arch Ophthalmol 1978;96: 77-83.

8 Wyzinski P, Rootman J, Wood W. Simultaneous bilateral iris metastases from renal cell carcinoma. Am $\mathcal{F}$ Ophthalmol 1982; 92: 206-9.

9 Archer DB, Gardiner TA. An ultrastructural study of carcinoid tumor of the iris. Am $f$ Ophthalmol 1982; 94: 357-

10 Kurosawa A, Sawaguchi S. Iris metastasis from squamous cell carcina A, of the urerine cervix. Arch Ophthalmol 1987; 105: 618 .

11 Levine RA, Williamson DE. Metastatic carcinoma simulating a postoperative endophthalmitis. Arch Ophthalmol 1970; 83: $59-60$.

12 Morgan WE III, Malmgren RA, Albert DM. Metastatic carcinoma of the ciliary body simulating uveitis: diagnosis by cytologic examination of aequous humor. Arch Ophthalmol 1970; 83: 54-8.

13 Freeman TR, Friedman AH. Metastatic carcinoma of the iris. Am $\mathcal{F}$ Ophthalmol 1975; 80: 947-52.

14 Woog JJ, Chess J, Albert DM, Dueker DK, Berson FG, Craft J. Metastatic carcinoma of the iris simulating iridocyclitis. J. Metastatic carcinoma of the iris

15 Shields CL, Shields JA, Shields BM, Augsburger JJ. Prevalence and mechanism of secondary intraocular pressure elevation in eyes with intraocular tumors. Ophthalmology 1987; 94: 839-46.

16 Naumann GOH. Mucogenic open angle glaucoma produced by metastatic carcinoma. Case presentation to the Verhoeff Society, Baltimore, Maryland, April 1985.

17 Denslow GT, Kielar RA. Metastatic adenocarcinoma to the anterior uvea and increased carcinoembryonic antigen levels. Am 7 Ophthalmol 1978; 85: 363-7.
18 Scholz R, Green WR, Baranano EC, Erozan YS, Montgomery BJ. Metastatic carcinoma to the iris. Ophthalmology 1983; 90: 1524-7.

19 Rotkis WM, Kulander BG, Chandler JW, Kaiser FS. Diagnosis of anterior chamber metastasis by serologic marker found during anterior chamber paracentesis. $A m \mathcal{F}$ Ophthalmol 1986; 102: 179-81.

20 Michelson JB, Felberg NT, Shields JA, Foster L. Carcinoembryonic antigen positive metastatic adenocarcinoma of embryonic antigen positive metastatic adenocar

21 Michelson JB, Felberg NT, Shields JA. Metastatic adenocarcinoma. Am $\mathcal{F}$ Ophthalmol 1978; 86: 142-3.

22 Michelson JB, Felberg NT, Shields JA. Carcinoembryonic antigen. Its role in the evaluation of intraocular malignant tumors. Arch Ophthalmol 1976; 94: 414-6.

23 Daicker B. Metastatische Tumoren in der Uvea. Klin Monatsbl Augenheilkd 1981; 178: 329-36.

24 Zimmerman LE. The remarkable polymorphism of tumors of the ciliary epithelium. The Norman McAlister Gregg lecture. Trans Aust Coll Ophthalmol 1970; 2: 114-25.

25 Shields JA, Augsburger JJ, Wallar PA, Shah HG. Adenoma of the nonpigmented epithelium of the cilary body. Ophthalmology 1983; 90: 1528-30.

26 Jakobiec FA, Zimmerman LE, Spencer WH, Slaktor JS, Krebs W. Metastatic colloid carcinoma versus primary carcinoma of the ciliary epithelium. Ophthalmology 1987; 94: 1469-80.

27 Markoe AM, Brady LW, Grant GD, Shields JA, Augsburger JJ. Radiation therapy of ocular disease. In: Perez CA, Brady LW, eds. Principles and practice of radiation oncology. Philadelphia: Lippincott, 1987: 456-8.

28 Sierocki J, Charles N, Schafron KM, Eamittes R. Carcinoma metastatic to the anterior ocular segment. Cancer 1980; 45: 2521-3. 